\title{
MOBILITY AND VISUAL IMPAIRMENT
}

\author{
Thomas Keller ${ }^{1}$, Markus Rüttimann ${ }^{2}$ and Alireza Darwishi ${ }^{3}$ \\ ${ }^{I}$ ZHAW School of Management and Law, Winterthur, Switzerland \\ ${ }^{2}$ Trapeze Switzerland GmbH, Neuhausen am Rheinfall, Switzerland \\ ${ }^{3}$ ZHAW School of Engineering, Winterthur, Switzerland
}

\begin{abstract}
The aim of this work is to help visually impaired and blind people to benefit equally from digitization in public transport. It consolidates the requirements that visually impaired and blind people place on an assistance system to facilitate their daily use of public transport. These requirements should make it easier for those affected and their associations to communicate with specialist groups in the industry and with clients in order to be able to implement or consider a suitable assistance system in a project more quickly and in a more targeted manner.
\end{abstract}

\section{KEYWORDS}

Visual Impairment, Public Transport, IP-KOM-ÖV, User Information System, Digital Assistant

\section{INTRODUCTION}

The digitization of public transport has accelerated considerably in recent years and enables transport companies to offer their customers end-to-end digital services along the entire mobility chain.

It is difficult for visually impaired people to use public transport efficiently. The available assistants are of less use to this group because they have not been developed specifically for their needs. Requirements that allow orientation at the stop or interaction with the public transport infrastructure or present passenger information in a way that meets their needs are not, or not sufficiently, implemented.

The problems with which visually impaired and blind people are confronted in their daily use of public transport were recorded in conducted interviews, evaluated and normalized using scenarios. Afterwards, requirements for an assistance system were elaborated, which on the one hand addresses the problems raised and on the other hand integrates the system into a current architectural standard in the industry.

The problem analysis was able to show which are the relevant information and interaction problems and which compensation strategies the interviewees use to master these problems.

The solution concept was able to show that the information deficit can already be completely eliminated today with a suitable assistance system. All relevant information is available in digital form and via suitable interfaces in every modern control system. The use cases in this area define which information is relevant when and how it can be presented in order to offer the user added value.

The requirements, which enable the interaction possibilities of the users with a vehicle or the running operation, show that the standardization of the industry in this area is not advanced enough, in order to be able to convert an assistance system thereby. The solution concept shows which functions and data are still missing and how the existing interfaces can be extended.

The findings of this work should help stakeholders and their organizations to develop a common vision of an assistance system and to implement it together with transport companies and associations within the framework of legislation for barrier-free mobility. 


\section{RESEARCH DESIGN}

The following subchapters show schematically the phases of the selected research design.

\subsection{Conducting the Interviews}

At the beginning of the work, a guided interview by telephone was conducted with visually impaired and blind people in order to determine the everyday difficulties in dealing with public transport and the individual compensation strategies. The interviews usually lasted one hour. The interviews are based on a specially developed guideline. After each interview, the guideline was adapted to the current state of knowledge on the subject in order to be able to verify the findings in the next interview. (Kai Niebert, Harald Gropengiesser, 2014).

\subsection{Synthesis of the Findings}

In the next step, the individual problems and coping strategies were synthesized from the interviews. The interviews were summarized in writing and the statements were grouped thematically. Then these statements together with the mentioned coping strategies were summarized in a table and assigned either to the stop or to the vehicle. In order to support the next step of the requirements modelling the persona "Diane" was developed. (Chris Rupp, die SOPHISTen, 2014).

\subsection{Elaboration of the Solution Concept}

During the development of the solution concept, in a first step survey scenarios were developed which describe the planned assistance system in use in a real environment (Chris Rupp, die SOPHISTen, 2014). These survey scenarios support a user-centered approach by associating individual problems with the persona Diane and describing the direct interaction between the actuators (Rosson, Carroll, 2002). In a second step, use cases were created, taking into account the defined objectives. In a third step, activity diagrams were created to identify and functionally decompose the system interfaces.

\subsection{Validation of the Solution Concept}

In an expert discussion with the Technology and Innovation Unit of the Swiss Federation of the Blind and Visually Impaired (SBV) in Berne, the problems and the solution concept were validated. The findings gained during the validation process were fed back into the solution concept.

In order to complete the validation, the findings gained in this work were compared with the results of the aim4it project and with INTROS (Schnieder, Kohl, Weißer, 2016), (Sehbehindertenverband, 2018).

\subsection{Autonomous Mobility}

The findings concerning autonomous vehicles were dealt with in a separate part of the work. These findings are relevant for visually impaired and blind people because of the lack of a driver and are therefore of a general nature. These cross-sectional requirements have been incorporated into the solution concept, as it has to do without the driver from this point of view. Other findings are not only relevant for visually impaired and blind people. These were listed separately, but are not in the focus of this work. 


\section{SOLUTION CONCEPT}

In this chapter the use cases of the assistance system are presented on the basis of the results from the interviews and their synthesis, the scenarios. The presentation of the interviews and scenarios are omitted for the sake of brevity ${ }^{1}$. The aim is to develop the interactions of the actors and the behavior of the assistance system until the functional requirements of the system interfaces and the conceptual data model can be derived.

\subsection{Conceptual Architecture}

The system in the center represents the assistance system. The system context is the part of the environment that interacts with the assistance system and is relevant for understanding the requirements. "The system context anticipates the integration of the system in reality and identifies those aspects that relate to the system" (Pohl, Rupp, 2015). The systems of the irrelevant environment serve the superordinate understanding and are not relevant for this work.

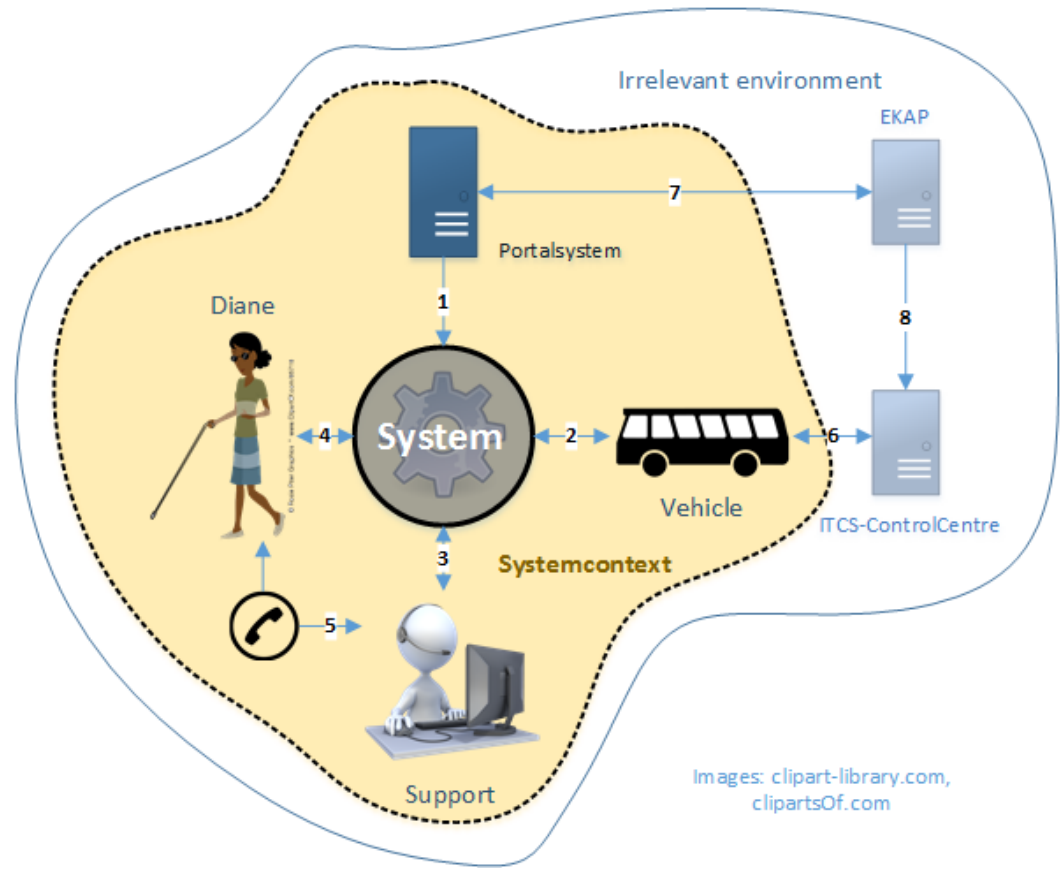

Figure 1. Solution space

Portal system: According to the VDV reference architecture (VDV-430, 2014), the portal system is the integration point for mobile applications. The portal system represents an actor in the solution concept and communicates with the assistance system via interface 1. The TRIAS interface definition intended for integration is defined in the standards (VDV-431-1, 2014) and (VDV-431-2, 2014).

Vehicle: According to the VDV reference architecture (VDV-301-1, 2014), the vehicle is the integration point for the customer terminal in the vehicle. The vehicle represents an actor in the solution concept and communicates with the assistance system via interface 2 . The functions intended for integration are defined in the service module "Customer communication functions" of the VDV-301.

Support: The actor support represents the personal assistance available to the user of the assistance system. This role can be performed both by an organization and by a trusted person. The support communicates via interface 3 whose requirements are included in the use cases. Interface 5 represents an ordinary telephone connection.

${ }^{1}$ The complete documentation is available online at

https://zhaw-my.sharepoint.com/:b:/g/personal/kell_zhaw_ch/Ee8wh06OOWJEur3hurfj3VgBVcGwvbMOKnjV4wpaYFUB4Q 
Diane: Persona Diane is the user of the system and communicates with the assistance system via interface 4. Since this work does not deal with the specific user interface of the assistance system, the specification of this interface is limited to the interactions described in the use cases.

\subsection{Derived Use Cases}

The following Figure 2 gives an overview of the derived use cases and their categorization into the groups "stop", "vehicle" and "general use cases".

The decomposition of the scenarios into individual function groups during the system analysis has shown that individual functions or use cases should be available at all times or have a cross-sectional character. These use cases were assigned to the group "General use cases".

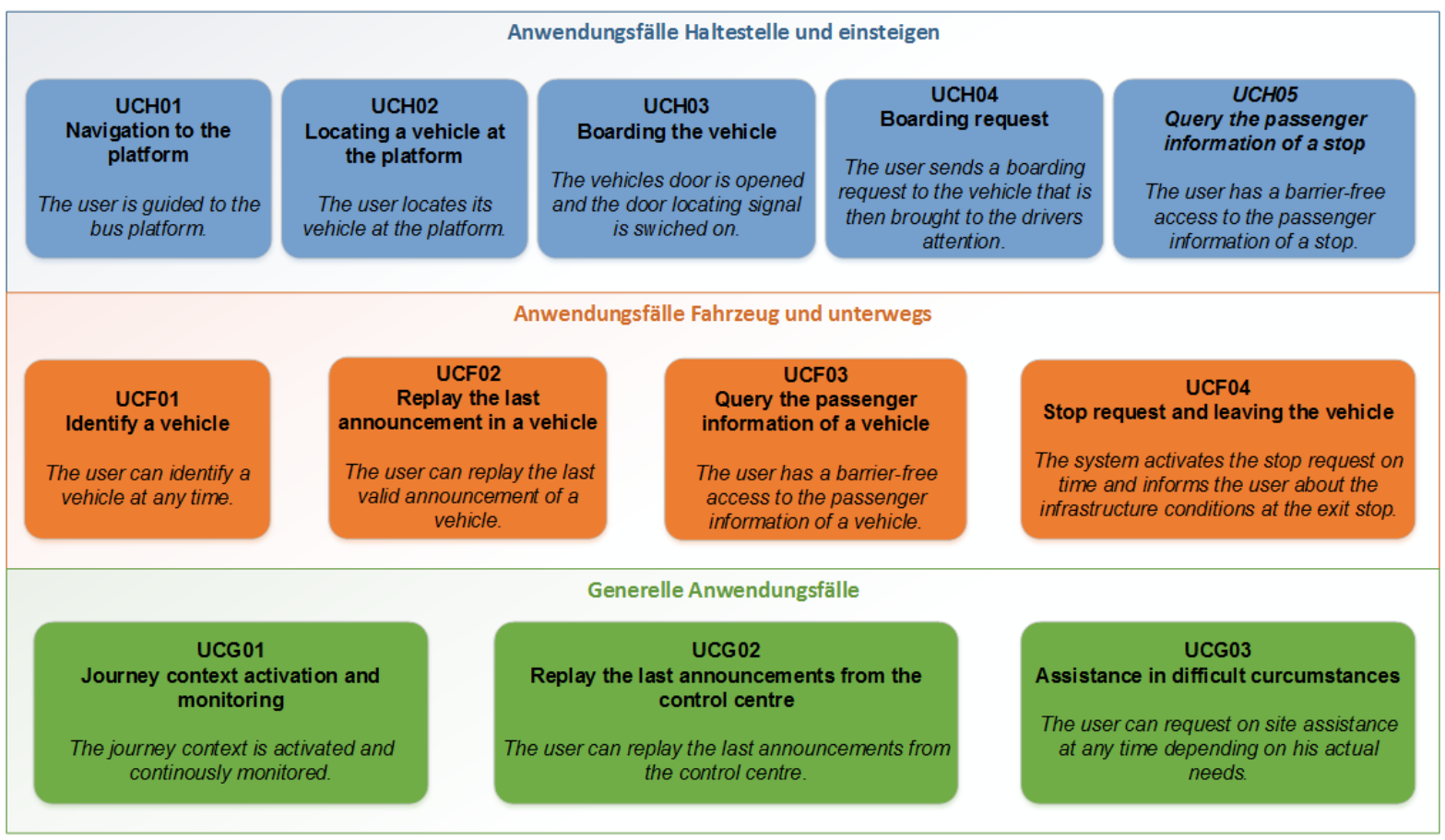

Figure 2. Overview of derived use cases

The interaction with the environment was modeled for each use case in an activity diagram (not shown in this paper). The focus of the modeling was on the interaction with the system context via interfaces 1, 2 and 3 with the aim of estimating the integration capability of the assistance system into the VDV reference architecture.

\subsection{Usability}

The usability analysis of an application, which implements the use cases of the solution concept, is not part of this work. Nevertheless, the requirement "autopilot", which was mentioned in the problem definition and during the validation by the expert as decisive for the usability of the system as a whole, is included in the solution design.

The assistance system must be equipped with an autopilot that enables the individual use cases to be linked together automatically and meaningfully without restricting the user's freedom of movement. This means that the user has his hands free for everyday tasks. The assistance system should work "out of the pocket".

This requirement is essential for the usability of the assistance system. A visually impaired person will typically want to hold a cane and/or a guide dog by one hand. In addition, there is also the need to have a hand for touching and holding stair railings, etc. available. 
For the design of the application, this means that all outputs have to be realized acoustically, e.g. via bone conduction headphones, as well as inputs via discrete keys on the cane, on clothing (wearables) or via speech, so that the assistance system does not have to be held in the hands.

The use cases of the solution concept already consider the autopilot as well as the speech output, but the input function was not considered.

\subsection{Comparison with "aim4it" and "INTROS"}

Table 1 compares this solution concept with the use cases realized in the above-mentioned projects. "No" means that the corresponding project does not implement the use case. "Yes" means that the use case was implemented in the same or comparable way.

Table 1. Comparison of derived use cases with findings from other projects

\begin{tabular}{|c|c|c|c|}
\hline Use Case & Priority & aim4it & INTROS \\
\hline UCH01 Navigation tot he platform & 2 & Yes & No \\
\hline UCHO2 Locating a vehicle at the platform & 1 & No & Yes \\
\hline UCHO3 Boarding the vehicle & 1 & \multicolumn{2}{|c|}{ Yes } \\
\hline UCHO4 Requesting boarding & 1 & Yes & Yes(1) \\
\hline UCH05 Query passenger info of a stop & 1 & Yes & No \\
\hline UCF01 Identify a vehicle & 1 & \multicolumn{2}{|c|}{ Yes(2) } \\
\hline UCF02 Replay the last announcement in a vehicle & 3 & \multicolumn{2}{|c|}{ No } \\
\hline UCF03 Query passenger info of the vehicle & 1 & \multicolumn{2}{|c|}{ Yes } \\
\hline UCF04 Stop request and leaving the vehicle & 2 & Yes & Yes(3) \\
\hline UCG01 Journey context activation and monitoring & 1 & \multicolumn{2}{|c|}{ Yes } \\
\hline UCG02 Replay the last announcement of the control centre & 2 & \multicolumn{2}{|c|}{ No } \\
\hline UCG03 Assistance in difficult circumstances & 2 & \multicolumn{2}{|c|}{ No } \\
\hline Usability aspect „Autopilot" & 1 & \multicolumn{2}{|c|}{ No } \\
\hline $\begin{array}{l}\text { [1] Only direct communikation with vehicle } \\
\text { [2] No explicit identification possible } \\
\text { [3] No infrastructure and construction site information }\end{array}$ & & & \\
\hline
\end{tabular}

The direct comparison shows that all use cases of this solution concept, especially those with priority 1 , are the same or at least have a similar effect in both other projects. Additionally, use cases UCF02, UCG02 and UCG03 together with the autopilot functionality have been identified by the problem-oriented proceeding.

\section{CONCEPTUAL DATA MODEL AND INTERFACES}

This chapter describes the conceptual data model and the interfaces of the use cases which are not included in the IP-KOM-ÖV standard. The aim is to get an overview of the missing data structures and interfaces which are necessary for the implementation of the system.

\subsection{Vehicle Meta Information}

The data model as depicted in Figure 3 defines the information about the current equipment in the vehicle. The equipment defines which functions are available to the assistance system. The model also contains information about possible vehicle defects that could limit the functionality of the assistance system or the usability of the vehicle. 


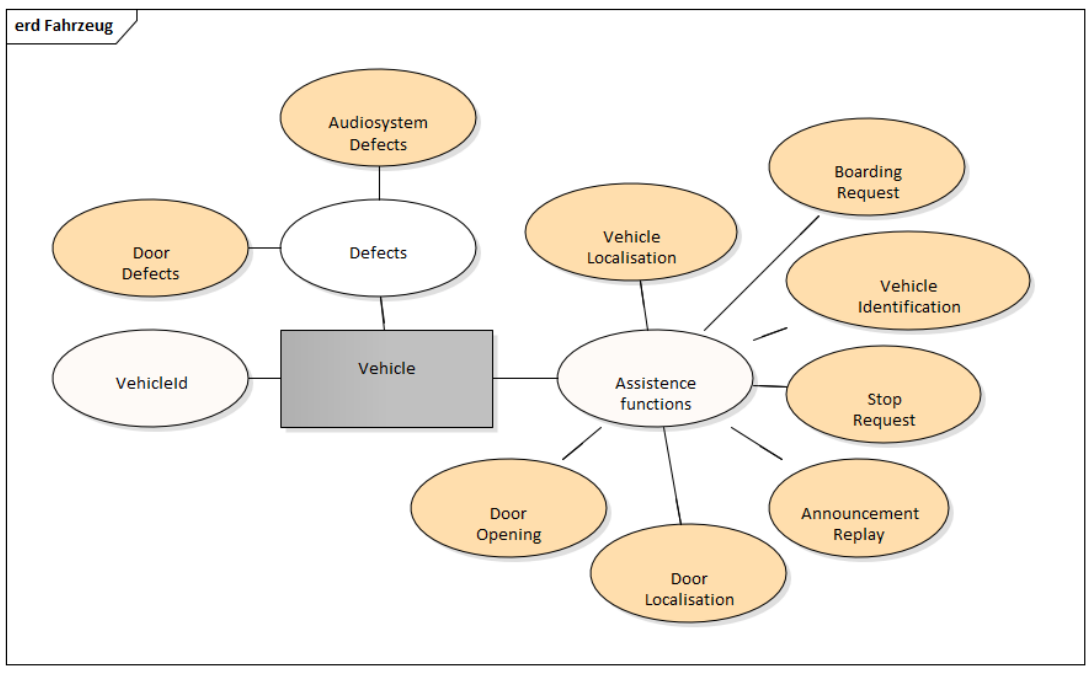

Figure 3. Datenmodell Fahrzeug

Vehicle defects: This attribute contains all vehicle equipment defects that are relevant for a visually impaired person.

Vehicle functions: This attribute lists all functions available to the assistance system in a specific vehicle.

\subsection{Infrastructure Meta Information}

The data model as depicted in Figure 4 defines the information about the current state and characteristics of the infrastructure of a particular stop.

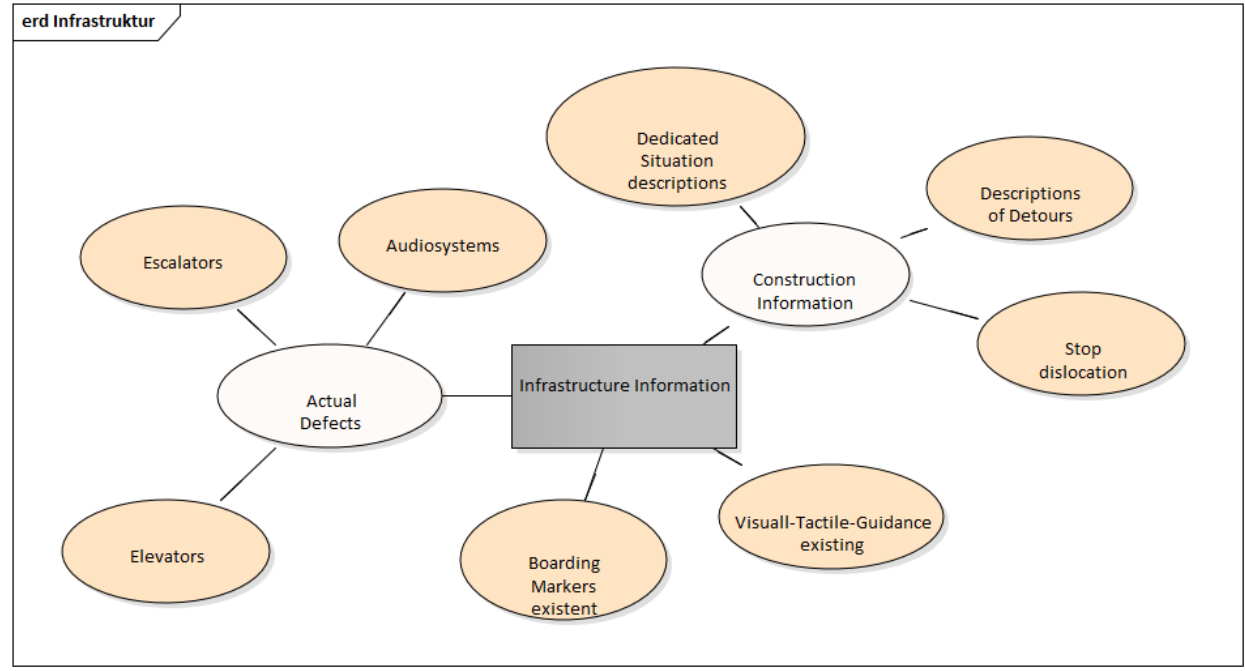

Figure 4. Datenmodell Infrastrukturmodell

Boarding marker and visual tactile guideline available: These attributes inform the user whether the stop has a boarding marker and is integrated into the tactile guidance system.

Current defects: The information about the current defects or malfunctions at the stop infrastructure are available in an IP-KOM-ÖV compliant system and are only listed here for the sake of completeness. It should be noted, however, that this information must be recorded according to requirements. See also (Bartz, Stegemann, Feldmann et al., 2018). 
Construction site information: This attribute informs about the current construction activity at the stop. This information is available in an IP-KOM-ÖV-compliant system, but is usually not recorded according to requirements. Information about necessary detours, where a stop has been exactly moved to or a visually impaired compliant description of the situation on site is often missing. See also (Bartz, Stegemann, Feldmann et al, 2018).

\subsection{Interaction with the Vehicle}

The interaction with the vehicle is realized via interface 2 (see Figure 1). This interface is not defined in any standard yet and is therefore an extension. It must fulfill the following functions:

- Function ,door localization and opening“

- Function „boarding vehicle“

- Function ,vehicle identification“

- Function „repeating announcement“

- Function „passenger information within the vehicle“

- Function „,disembarking vehicle“

\subsection{Help and Support}

The interface 3 required for interaction with a support or help team (see Figure 1) and the necessary service infrastructure are not defined in any standard yet. It must fulfill the following functions:

- Function "Information and questions “"

- Function „Assistance and Orientation“

- Function „Personal contact“

\section{CONCLUSION}

The surveys of visually impaired and blind people on the everyday challenges of travelling in public transport have revealed a very homogeneous picture of the problem domain. All respondents reported the same problems from their personal point of view, regardless of how often they use public transport. The biggest problem is that they have too little relevant information from the areas of dynamic passenger information, vehicle location, route guidance and orientation on the way.

The requirements defined in the solution concept can reduce the information deficit at the stop and on the way in the vehicle by making available at least the same information as for the seeing passengers in a needs-based, timely and interactive manner. The analysis of the necessary data has shown that these already exist in a system specified according to IP-KOM-ÖV.

The requirements defined in the solution concept also enable personal interaction with the infrastructure as well as ongoing operations via the control centre. Vehicles can be located and identified at the stop and the doors can be opened. On the way, the visually impaired or blind passenger in the vehicle is informed in good time of the approaching exit and of the conditions at the exit stop.

The functions required for interaction with the vehicle, with the support team and for providing the announcements of the control centre are not contained in any standard and must therefore be defined as an extension of any standard. The solution concept was able to show the necessary functions and interfaces.

The specific requirements of visually impaired and blind people for the operations of autonomous vehicles in public transport could not be considered in detail due to the lack of experience of the interviewed persons. However, the findings gained in this area show that the requirements of normal passenger transport are also valid for autonomous operation and that the priority for the availability of direct human assistance must be given greater weight.

In the conception of the solution, requirements for an assistance system that addresses the most relevant problems of the target group could be determined. The technical basis of the conception was laid in such a way that it is based on a common standard in the industry, which facilitates the integration capability and thus favors a quick and broad availability of the system. 
The aspect of user-friendliness (usability) was only taken into account with the function of the "autopilot". The realization of this requirement requires a certain intelligence in the concatenation of the individual use cases, which must at least interpret the current traffic situation and travel planning. The system must also have voice control. These are interesting topics, which should be deepened further.

\section{REFERENCES}

Amotech. (1. 12 2018). Verkehrsbetriebe Schaffhausen fahren autonom. Von Amotech.ch: https://www.amotech.ch/de/media-center/detail/verkehrsbetriebe-schaffhausen-fahren-autonom abgerufen

Bartz, Stegemann, Feldmann u.a. (20. 5 2018). Grundlagen und Umsetzungsempfehlungen zur Bereitstellung einheitlicher Informationen zur Barrierefreiheit im Öffentlichen Personenverkehr. Von Barrierefreie Reiseketten in der Fahrgastinformation:

https://www.delfi.de/sites/default/files/library_entries/DELFI_Handbuch_Barrierefreie_Reiseketten_1.\%20Auflage\% 20Mai\%202018.pdf abgerufen

BMVIT, Ways4all. (2011). Von Ways4all Projektreihe: http://ways4all.at abgerufen

Chris Rupp, die SOPHISTen. (2014). Requirements-Engineering und -Management Aus der Praxis von klassisch bis agil. München: Hanser, Carl.

Dölger, Giemula, Henninger, Roß. (2015). Die Strategie DELFI-2020. Der Nahverkehr, 9, 36-41. Von https://www.delfi.de/sites/default/files/library_entries/Der\%20Nahverkehr\%2009-2015\%20Strategie\%20DELFI2020.pdf abgerufen

hindernisfreie-architektur. (2005). Leitliniensystem Schweiz. Von hindernisfreie-architektur.ch: https://hindernisfreiearchitektur.ch/wp-content/uploads/2017/01/MB_114_Leitliniensystem.pdf abgerufen

Kai Niebert, Harald Gropengiesser. (2014). Leitfadengestützte Interviews. In H. S. Dirk Krüger, Methoden in der naturwissenschaftsdidaktischen Forschung. Berlin: Springer. doi:10.1007/978-3-642-37827-0_10

Pohl, Rupp. (2015). Basiswissen Requirementsengineering. Heidelberg: dpunkt.verlag.

Rosson, Carroll. (2002). Scenario-Based Design. In J. Jacko, \& A. Sears, The Human-Computer Interaction Handbook: Fundamentals, Evolving Technologies and Emerging Applications (S. 1032-1050). Lawrence Erlbaum Associates.

SBB. (9. 1 2019). Von SBB Call Center Handicap: https://www.sbb.ch/de/bahnhof-services/reisende-mit-handicap/sbbcall-center-handicap.html abgerufen

Schnieder, Kohl, Weißer. (Juni 2016). Barriefreie Mobilität: Reiseassistenz mittels Smartphone. Der Nahverkehr, S. 6-11.

Sehbehindertenverband, S. S.-u. (23. 10 2018). ÖV-App für Blinde und Sehbehinderte. Von Newstix.de: https://www.newstix.de/index.php?site=\&entmsg=true\&ref=RNL\&mid=43446 abgerufen

VBZ. (30. 6 2018). VBZ_Schadenstatistik. Von www.stadt-zuerich.ch: https://www.stadtzuerich.ch/content/dam/stzh/vbz/Deutsch/Ueber\%20das\%20Departement/Medienmitteilungen/2018/Halbjahres_VBZ _Schadenstatistik\%202012\%20-\%2030.06.2018.pdf abgerufen

VDV, IP-KOM-ÖV. (2014). Internet Protokoll basierte Kommunikationsdienste im öffentlichen Verkehr. Von IP-KOMÖV: http://www.ip-kom.net/ abgerufen

VDV-301-1. (2014). Internetprotokoll basiertes integriertes Bordinformationssystem IBIS-IP (Bd. Teil 1). Verband Deutscher Verkehrsunternehmer (VDV). Von https://www.vdv.de/vdv-301-1-ibis-ip-teil-1-systemarchitektur.pdfx abgerufen

VDV-430. (2014). VDV-430 Mobile Kundeninfromation im ÖV. Verband Deutscher Verkehrsunternehmen (VDV).

VDV-431-1. (2014). Echtzeit Kommunikations- und Auskunftsplattform EKAP (Bd. Teil 1). Verband Deutscher Verkehrsunternehmen (VDV).

VDV-431-2. (2014). Echtzeit Kommunikations- und Auskunftsplattform EKAP (Bd. Teil 2). Verband Deutscher Verkehrsunternehmen (VDV). 